\title{
Determination and Ranking of Effective Advertising Media Employed by Iran Private Banks Using Analytical Hierarchy Process Technique
}

\author{
Arshad Hedayati ${ }^{1}$, Arvin Fouladifar ${ }^{2} \&$ Elham Taghipour ${ }^{3}$ \\ ${ }^{1}$ Department of Business Management, Faculty of Economics, Management and Administrative Sciences, \\ Semnan University, Semnan, Iran \\ ${ }^{2}$ University of Nice Sophia Antipolis, Iran \\ ${ }^{3}$ University Pierre Mendes Grenoble, Iran \\ Correspondence: Arshad Hedayati, Department of Business Management, Faculty of Economics, Management \\ and Administrative Sciences, Semnan University, Semnan, Iran. Tel: 98-912-396-3996. E-mail: \\ arshad.hedayati@gmail.com
}

Received: April 29, 2016

Accepted: May 7, 2016

Online Published: May 27, 2016

doi:10.5539/mas.v10n9p60

URL: http://dx.doi.org/10.5539/mas.v10n9p60

\begin{abstract}
Banks use various advertisingmediato develop their marketing plans.However, all the advertising media have not the same impacts on the economic growth of banksas their efficiencies are influenced by several technical and socialfactors. In this study, we investigate the importance of various advertising media on the progress of Iran private banks based on the evaluation of some important parameters such asthe media cost, geographical selection power, audiences' media habits, type of the advertising message and advertisements of competitor banks.In this regard, television, newspapers and magazines, radio, and billboard and sport fields are selected as the mainmedia for the banks commercial activities. Using the analytical hierarchy process (AHP) method, the media cost with the importance of $34.3 \%$ is the main parameter and the type of the message with the importance of $10.2 \%$ is the least important factor influencing the selection of media by the banks for the advertisement operations. The results show that the effectiveness of advertising media is different sincetelevision with the importance of $47.3 \%$ is placed in the first level and the billboard and sport fields with $9 \%$ importance is in the last place. In general, the order of priority of advertising media is:television $>$ newspapers and magazines $>$ radio $>$ billboard and sport fields. This study offers insight into the development of analysis for the selection of effective advertisingtools based on the factors related to the advertisement properties and the community behavior.
\end{abstract}

Keywords: advertising media, banks, Ranking, analytic hierarchy process

\section{Introduction}

In today's world, companies have found out that getting reputation is very difficult and loosing that is very easy. Today, mass markets are converting to smaller ones. Distribution channels are developing. Advertising cost through media is increasing and simultaneously this advertisement's effectiveness is decreasing. Therefor old methods of business must be revised (Cutler, 2001).

It is more than one decade that private banking has started to work in monetary and financial market and have been able to own more than $25 \%$ of country's monetary market because of efficient management and young educated human capital. But because of more limited financial sources (than governmental competitors), accountability to stakeholders, noting optimal and economic doing of its affairs, the existence of governmental competitors, this system should seek efficient and effective advertising activities to achieve their determined goals.

After passing relaxed and non-competitive period, Iran's banking system has been developed and changed for about one decade, these developments has been created in system under the influence of several factors such as informational and technologic changes, the increasing importance of services and customer retention, entry of private banks, increasing advertising activities and so on.

Banks use various methods (TV, radio, newspaper and ...) for advertising their services and activities and spend high cost in this way. In such an environment, because of various limitations and necessities such as limited financial sources, accountability to stakeholders, and the existence of big governmental competitors, private 
banks should seek efficient and effective advertising activities to achieve their determined goals. It seems that recognition of effective factors in choosing advertising media, determining and ranking appropriate advertising media can be useful for economizing on financial resources, accessing to target customers and performing effective advertisement.

Advertisement: advertisement is one of the most common tools that companies use them to lead their persuading communication to their target buyers and communities. Advertisement is defined as: each kind of impersonal progress and proposing ideas, goods or services by an advertiser which performing that requires paying cost (Bahman Foroozandeh, Cutler, 2003).

Advertisement position in marketing process: JorumMc Cartier proposed combination or marketing elements concept which included four main factors; product, price, distribution and promotion in early 1960s and organized marketing literature. These four factors are traditionally considered as $4 p$ (combination or marketing elements). These $4 \mathrm{P}$ are each kind of action that a company can take for its products and services and in order to affecting demand. Because many marketing experts such as Cutler and Armstrong believe that marketing management in fact is that very demand management, creating demand, regulate the level of demand, timing and demand specifications (Mohammadian, 2003).

Planning advertisement: planning advertisement coordinates appropriate message for appropriate contact and for accessing to contact, propose it from an appropriate media. In another word three main elements form advertising strategy:

Considering contact: who are you trying to achieve?

Message strategy: what do you want to tell them?

Media strategy: when and where will you achieve them?

At the time of providing an advertising program, marketing managers must always begin their work with identifying and defining target market and buyers' motivations then they have to make five main decisions for providing an advertising program. These decisions which are known by $5 \mathrm{M}$ are:

Mission: what are the goals of advertisement?

Money: how much money can be allocated to this?

Message: what message must be sent?

Media: which media must be used?

Measurement: how the results can be evaluated? (Forouzandeh and Cutler, 2003)

Media's planning operation: To achieve key goals of plan, who (goal), where (place), when (time framework), how long (course duration), planners of the media use a selection process for better selecting of replacements and methods in providing plan needs. Below discussion investigates some usable strategies for achieving company's goals.

a) Geographical strategies: when sales' patterns of a regional or global trader aren't harmonic, media planner often has to balance market in terms of advertisement and sale with investment. Used rule in allocating advertisement costs may use each one or all market's statistics which are: target population, distribution and related costs to media balancing and also obtained results of company's sales.

b) Timing strategies/ course duration: the time of advertisement can have various meanings that include seasons, months or some parts of day but all of these are aligned with the concept of hole. The strategy of accomplishing these objectives requires balancing advertisement's available budgets with the duration of the advertising campaign (Wels et al., 2005).

Choosing the most effective pattern depends on the confiscation goals related to the nature of product, goal customers, distribution channels and other marketing factors. Attention to three factors is necessary at the time of choosing timing pattern. Buyer efficiency indicates a ratio which based on that new buyers enter the market and whatever this ratio is higher, advertisement should be more continuous. Purchase frequency is the number of times that a buyer buy the average of product during a period of time and whatever frequency is more, advertisement should be more continuous. Forgetting ratio is one where buyer forgets trade mark and whatever this ratio is higher, advertisement should be more continuous (Cutler, 2003). 


\section{Research Methodology}

\subsection{Sampling Method and Procedures}

Subjects were chosen from advertising experts working forthe private banks such as Pasargad, Parsian, Eghtesadenovin, Karafarin, Saman and Sina, and advertising companies in Iran. At the first step, by choosing 6-8 members from each institute, the total number of statistical society members were 43 . Considering that our statistical population is more than 30 people and the members are almost homogenous, indicating the normal distribution of population, the final subjects were sampled through stratified random sampling (systematic random sampling) using equation (1).

$$
n=\frac{N Z^{2} \frac{\alpha}{2} P(1-P)}{\varepsilon^{2}(N-1)+Z^{2} \frac{\alpha}{2} P(1-P)}
$$

where, $\mathrm{n}$ is the final number of subjects, $\mathrm{N}$ is the number of members of statistical population chosen from advertising experts in private banks (43 members), $\mathrm{P}$ is the ratio of people who were agree with the importance of various media for advertisement, which is considered as $50 \%$ to choose the maximum required sample, $\varepsilon$ is estimation error (0.07) and 1- $\alpha$ is confidence level ofresearch (95\%), which results in $Z=1.96$. As a results, the value of $\mathrm{n}$ was calculated to be 35 .

\section{2 Research Model Development and Data Collection}

Development of the hierarchy of decision in analytic hierarchy process is the most important issue.Therefore, in order to study the main aim of this work, i.e., ranking of advertising media based on the effective factors in the selection of a medium, the following steps were carried out.First,after studying available resources and interviewing with a number of bank's experts, three levels of hierarchy are identified to be used in ranking of advertising media. The goal, i.e., the ranking of theadvertising media, is placed in the first level. The main criteria in theselection ofa medium and various advertising media used by Iran's private banks occupy the second and third levels, respectively. Second, in order to find the most important factors for the aforementioned second level, a primary questionnaire including lots of variables was provided, which was filed out by the subjects. Using the results of the questionnaire, the factors which obtained score 7 from 9 were chosen as the parameters of the second level, which were the media cost, geographical selection power, audiences' media habits, type of advertising message, and advertisements of competitor banks.

Third, in order to select the main advertising media for the aforementioned third level, the researchers provided a primary questionnaire on the importance of various media for the banks advertisements which was filled out by banks employments. After analyzing the answers of questionnaires, four media includingtelevision, radio, newspaper and magazine, and billboard and sport fields were chosen for completion of the third level.Because of the common featuresof newspapers and magazines as well as billboards and sport fields, they are joined in the same groups. According to the above mentioned explanations, the hierarchical tree of this research can be illustrated in Scheme 1.

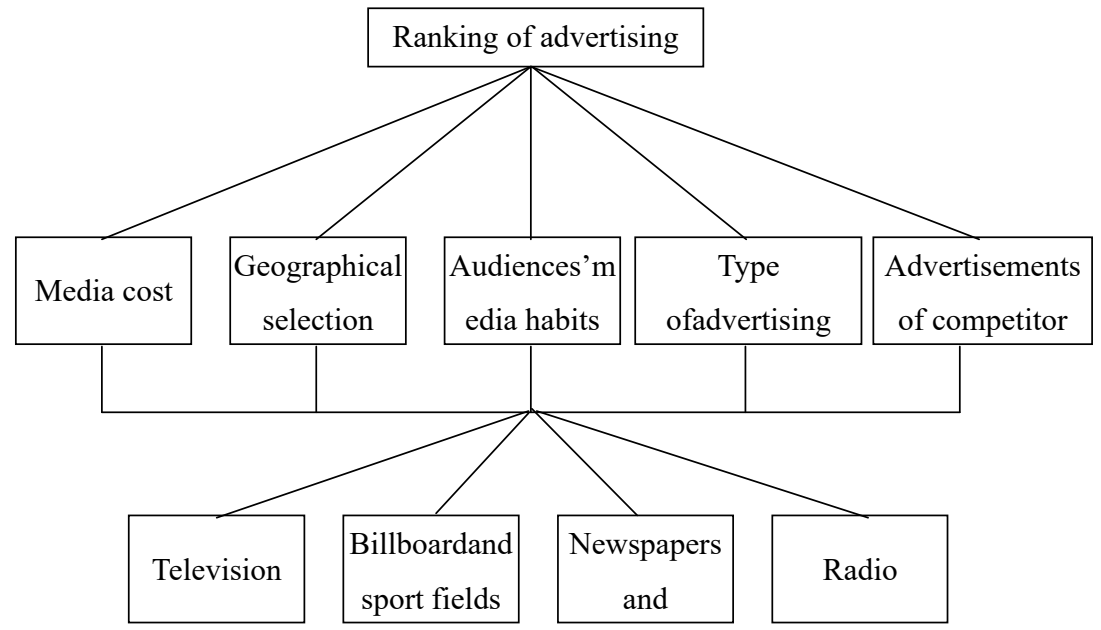

Scheme 1 . Hierarchy tree designed to rank the advertising media used by private banks 
Finally, the main questionnaire covering four aforementioned advertising media mostly used by banks and five effective factors in the selection of a medium was prepared. The questionnaire included 40 questions comprised of 10 questions on the comparison of the second level factors and 30 questions on the comparison of the third level materials with considering the second level variables. The questionnaires were filled out by 35 subjects and the obtained data were analyzed by EXCEL and EXPERT CHOICE software.

\section{Data Analysis and Results}

\subsection{Ranking of Media with Respect to Main Factors}

After collection of subjects answers to the main questionnaire prepared based on 4 media (i.e., television, radio, newspapers and magazines, and billboards and sport fields) and 5 effective factors (i.e., media cost, geographical selection power, audiences' media habits, type of advertising message and advertisements of competitor banks), the factor's relative weight, final weight and importance (an inconsistency ratio of 0.08 ) were calculated with respect to the goal of hierarchy tree (selection of advertising media), as summarized in Table 1.As the factors are directly connected to the goal, the relative weights and final weights are the same.

Table 1. Main criteria's relative and final weights, and their ranking

\begin{tabular}{llll}
\hline Criteria & Relative weight & Final weight & Rank \\
\hline Media cost & 0.343 & 0.343 & First \\
Geographicselection power & 0.158 & 0.158 & Fourth \\
Audiences' media habits & 0.207 & 0.207 & Second \\
Type of advertising message & 0.102 & 0.102 & Fifth \\
Advertisements of competitor banks & 0.189 & 0.189 & Third \\
\hline
\end{tabular}

Related calculations with EXPERT CHOICE software are shown in Table 2 and Figure 1.

Table 2. Comparing of the relative importance with respect to goal which obtained from EXPERT CHOICE calculations

\begin{tabular}{|c|c|c|c|c|}
\hline & AUDIENCE & COMPETTI & GEOGRAPH & MASAGE \\
\hline COST & $(1.2)$ & 1.5 & 4.0 & 4.0 \\
\hline AUDIENCE & & 1.0 & $(1.6)$ & 2.0 \\
\hline COMPETTI & & & 1.7 & 1.2 \\
\hline GEOGRAPH & & & & 1.6 \\
\hline
\end{tabular}

\begin{tabular}{|l|l|}
\hline \multicolumn{1}{|c|}{ Abbreviation } & \multicolumn{1}{c|}{ Definition } \\
\hline Goal & selecting the best media for bank advertising \\
\hline COST & cost \& efficiency \\
\hline AUDIENCE & audience favourity \\
\hline COMPETTI & compettitor's advertising \\
\hline GEOGRAPH & geographical selecting \\
\hline MASAGE & kind of masage \\
\hline
\end{tabular}

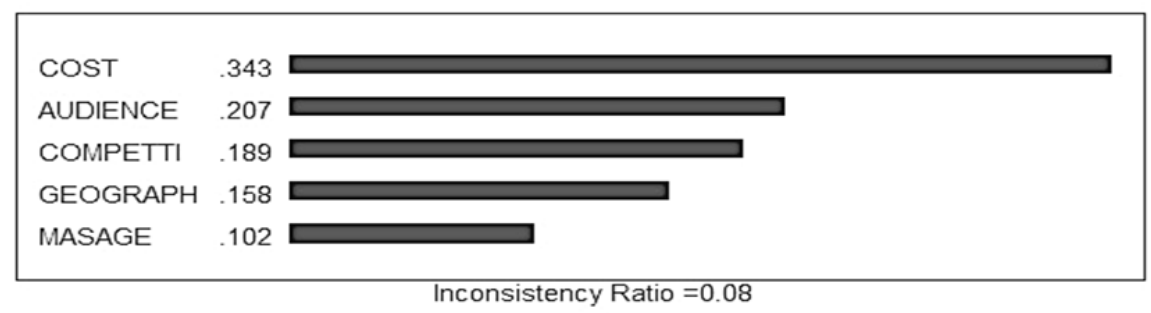

Figure 1.The results of analytic hierarchy process of media selecting factors

FromTable 1 and 2, and Figure 1,it can be seen that the main criteria influencing the choice of an advertising medium by the banks have different priorities. The criterion of the media cost is ranked in the first level with an 
importance of $34.3 \%$ and thecriterion of thetype of advertising message with the importance of $10.2 \%$ isplaced in the last level.Considering the validity ofthe AHP method and the good inconsistency ratio of 0.08 in the selected range of $0-0.1$, the obtained results are reliable confirming that the effective factors on the selection of advertising media are differently ranked.

Moreover, after collection of thesubjects'judgments on the questioner, the media's relative and final weights as well as the priority of these media were calculated. The results are summarized in Table 3 and Table 4.

Table 3. Information and calculations related to media according to all factors

\begin{tabular}{|c|c|c|c|c|c|c|c|c|c|c|}
\hline & \multicolumn{2}{|c|}{$\begin{array}{l}\text { Factor of } \\
\text { costandperformance }\end{array}$} & \multicolumn{2}{|c|}{$\begin{array}{l}\text { Thegeographicselection } \\
\text { of media }\end{array}$} & \multicolumn{2}{|c|}{$\begin{array}{l}\text { Audience media } \\
\text { trends }\end{array}$} & \multicolumn{2}{|c|}{ Type ofmessage } & \multicolumn{2}{|c|}{$\begin{array}{l}\text { Effect of rivals } \\
\text { advertising }\end{array}$} \\
\hline & $\begin{array}{l}\text { Relative } \\
\text { weight }\end{array}$ & $\begin{array}{l}\text { Final } \\
\text { weight }\end{array}$ & $\begin{array}{l}\text { Relative } \\
\text { weight }\end{array}$ & $\begin{array}{l}\text { Final } \\
\text { weight }\end{array}$ & $\begin{array}{l}\text { Relative } \\
\text { weight }\end{array}$ & $\begin{array}{l}\text { Final } \\
\text { weight }\end{array}$ & $\begin{array}{l}\text { Relative } \\
\text { weight }\end{array}$ & $\begin{array}{l}\text { Final } \\
\text { weight }\end{array}$ & $\begin{array}{l}\text { Relative } \\
\text { weight }\end{array}$ & $\begin{array}{l}\text { Final } \\
\text { weight }\end{array}$ \\
\hline TV & 0.369 & 0.126 & 0.52 & 0.082 & 0.52 & 0.123 & 0.472 & 0.048 & 0.472 & 0.114 \\
\hline $\begin{array}{l}\text { Newspapers and } \\
\text { magazines }\end{array}$ & 0.315 & 0.108 & 0.238 & 0.038 & 0.238 & 0.024 & 0.233 & 0.024 & 0.233 & 0.022 \\
\hline $\begin{array}{l}\text { Billboardandsport } \\
\text { fields }\end{array}$ & 0.114 & 0.039 & 0.085 & 0.013 & 0.085 & 0.016 & 0.054 & 0.006 & 0.054 & 0.012 \\
\hline Radio & 0.202 & 0.060 & 0.157 & 0.025 & 0.157 & 0.043 & 0.241 & 0.025 & 0.241 & 0.041 \\
\hline Compatibility-IR & 0.09 & & 0.09 & & 0.02 & & 0.08 & & 0.09 & \\
\hline
\end{tabular}

Table 4. Media's relative and final weights (final ranking)

\begin{tabular}{llll}
\hline Media & Relative weight & Final weight & Finalrank \\
\hline TV & 0.473 & 0.473 & First \\
Newspapers and magazines & 0.233 & 0.233 & Second \\
Billboardandsport fields & 0.09 & 0.09 & Fourth \\
Radio & 0.203 & 0.203 & Third \\
\hline
\end{tabular}

Related calculations to combining results in EXPERT CHOICE software are shown in Figure 2.

Synthesis of Leaf Nodes with respect to GOAL Ideal Mode

OVERALL INCONSISTENCY INDEX $=0.08$

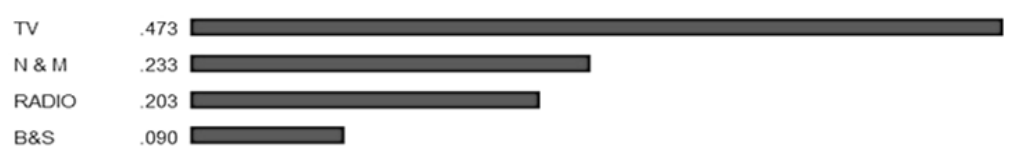

Figure 2. Media's final ranking obtained from EXPERT CHOICE calculations

According to Figure 2 and final tree (Scheme 2), media's final ranking is respectively; television with $47.3 \%$ in the first place, newspaper and magazines with $23.3 \%$ in the second place, radio with $20.3 \%$ in the third place and billboard and sport fields with $9 \%$ in the fourth or last place.

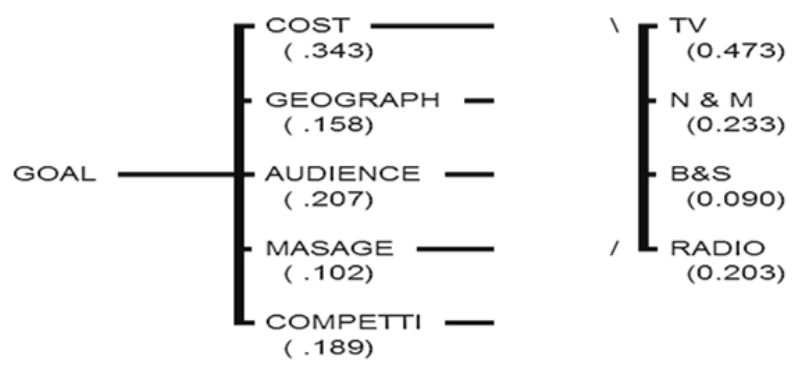

Scheme 2. Final ranked hierarchy tree 
According to related information to data analysis in different criteria for media and considering that inconsistency ratio is less than 0.1 in all levels and also because final matrix inconsistency is equal to 0.08 and reliable we can conclude that above media have different priorities and importance for private banks.

\subsection{Sensitivity Analysis}

Sensitivity analysis shows the effect of the changes in the input data or answers and consequently the effect of changes in the priority of media selection criteria on the importance of advertising media. Figure 3 represents the sensitivity analysisof advertising media based on the cost criterion (the most important criterion in the selection of media). The obtained final weight for the cost in this study (0.343) is shown with bold vertical line and the dynamic sensitivity analysis for this criterion is cleared with dotted line. It can be seen that by the changes in the priority of cost, the importance of the media is changed.By the increase of the cost weight value, the importance of the TV decreases, but the importance of the newspaper and magazines increases. The importance of the two other media (radio, and billboard and sport fields) remains relatively stable.

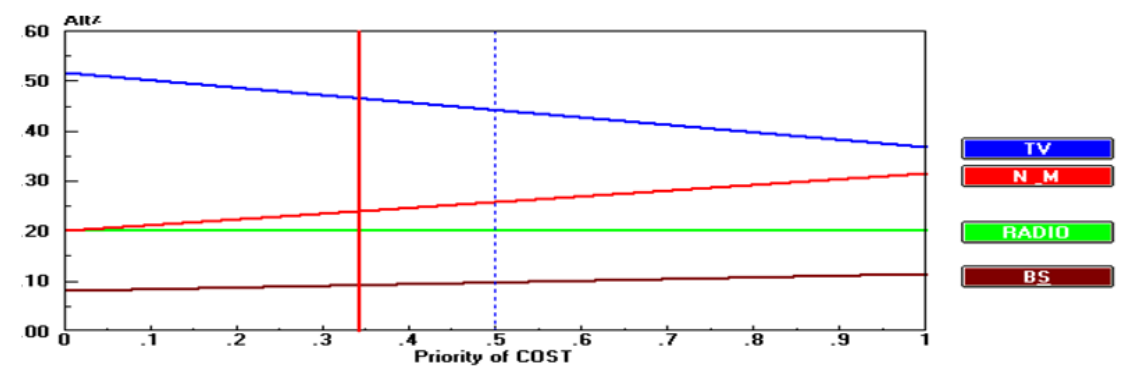

Figure 3. Sensitivity analysis based on cost variable

For example, Table 5 shows the changes in the priority and ranking level of advertising media bythe increase of the cost importance value from $34.3 \%$ to $50 \%$. Although the ranking of the media remains intact, the importance of the TV reduces by $3 \%$ and the importance of newspapers and magazines increase by $2.4 \%$.

Table 5. Changes in media priorities with change in media cost

\begin{tabular}{lllllll}
\hline & \multicolumn{2}{c}{ Beforechanges } & \multicolumn{2}{c}{ Afterchanges } & Amount & of \\
\cline { 2 - 5 } Media & Priority & Rank & Priority & Rank & changes \\
\hline TV & 0.473 & First & 0.443 & First & $-\% 3$ \\
Newspapers and magazines & 0.233 & Second & 0.257 & Second & $\% 2.4$ \\
Radio & 0.203 & Third & 0.203 & Third & $\% 0$ \\
Billboardandsport fields & 0.09 & Fourth & 0.097 & Fourth & $0.7 \%$. \\
\hline
\end{tabular}

The sensitivity analysis of contact's media habits is shown in Figure 4.From this figure, it is seen that, with increase of this criterion priority, the importance of TV increase, but the importance of the newspapers and magazines decreases gradually to the levels lower than the radio. There is not any considerable changes in the importance of two other media. For example, with the increase of the criterion 's importance value from $20.7 \%$ to $45 \%$, the priority of TV increase by $3.2 \%$ and the priority of newspapers and magazines decreases by $3 \%$. Therefore, as summarized in Table 6, TV preserves its first level in the ranking, but the importance of the newspapers and magazines decrease; thus placing in the third level.

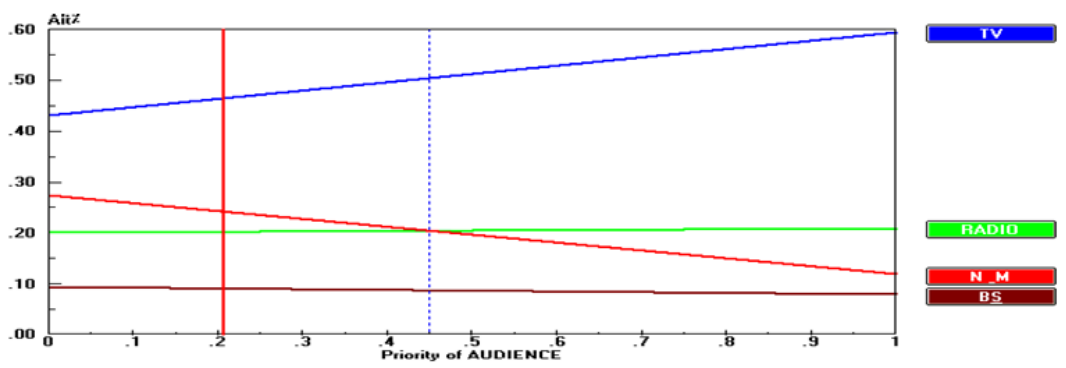

Figure 4. Sensitivity analysis of contacts' media habits based on slop after changes 
Table 6. Changes in media priorities with change in contacts' media habits

\begin{tabular}{llllll}
\hline & \multicolumn{2}{l}{ Beforechanges } & \multicolumn{2}{l}{ Afterchanges } & \multirow{2}{*}{ Amount of changes } \\
\cline { 1 - 5 } Media & Priority & Rank & Priority & Rank & \\
\cline { 1 - 5 } TV & 0.473 & First & 0.505 & First & $\% 3.2$ \\
Newspapers and magazines & 0.233 & Second & 0.203 & Third & $-\% 3$ \\
Radio & 0.203 & Third & 0.205 & Second & $0.2 \%$ \\
Billboardandsport fields & 0.09 & Fourth & 0.087 & Fourth & $-0.3 \%$ \\
\hline
\end{tabular}

\section{Conclusions}

In summary, the main media for advertising operations of private banks and the main criteria on the selection of the media were recognized, evaluated and ranked in this study. The hierarchy tree of the work, comprising of three levels i) propose of the work (selection of media, ii) main criteria influencing the selection of media and iii) main media for advertisement, was analyzed by the analytic hierarchy process technique.

The results showed that the main factors considered for the selection of media in the private banks have different priorities as ranked in the order of media cost $>$ audiences' media habits $>$ advertisements of competitor banks $>$ geographical selection power $>$ type of advertising message. It was also found that advertisement media have different importance not only with respect to each criterion but also in the final ranking. The advertisement mediahave various importance and priorities for private banks following the order of television $>$ newspaper and magazines $>$ radio $>$ billboard and sport fields.

Moreover, the sensitivity analysis showed that if the priority of criteria changes, television will be always in the first level as the important media. Therefore, although the cost is an important factor in the selection of the advertisement media and the television commercials cost higher prices than other advertisement methods, television is the most important media for the advertisement operations selected by the private banks. This study opens up new information for the banks to select the best medium or combination of media for their advertisement operations.

\section{References}

Anand, B. H. (2005). Planning for Power Advertising. Response Bookes. New Dahli.

Anthony, P., \& Elliot, A. (2004). Advertising Age, translated by DavoodSeyedEmami and Abbasi, Tehran: Soroush publications, Third editions.

Asgharpour, M. J. (2002). Multi-criteria decision making, Press center ofAmir KabirUniversity, Second edition.

Azar, A., \& Memariani, A. (1994-1995). AHP, A new technique for group decision-making, knowledge management, Tehran University, Faculty of Management, 27(28).

Azar, A., \& Rajabzadeh, A. (2002). Practicaldecision-making (M.A.M.D. Approach), NegaheDanesh publications, First edition.

David, J. (2004). Principles and Practice of Advertising. New York. McGraw Hill.

Ghodsipour, S. H. (2002), Discussionsonmulti-criteriadecision-making of Analytical Hierarchy Process (AHP), Press center ofAmir KabirUniversity, Third edition.

Howkinse et al. (2005).Consumer behavior. New York. McGraw Hill.

Kahraman, C. (2004). Multi-attribute Comparison of catering service Companies using Fuzzy AHP. International Journal of Production Economics, 87.

Kotler, P. (2003). Marketing Management, translated by BahmanForouzandeh, Atropat publications (1st Ed).

Kotler, P. (2006). Marketing Principles, translated by BahmanForouzandeh, Amookhteh publications(6th Ed).

Mohammadin, M. (2003). Advertising management, Horoufieh (2nd Ed).

Kwak, N. K., Chang, W. L., \& JiHee, K. (2005). An MCDM model for media selection in the dual consumer/industrial market, European Journal of Operation Research.

Saeed, M. G. (2002). A look at themarketing managementphilosophies, Refah Bank's management and marketing studies.

Tanaka, K. (2004). Introduction to fuzzy logicfor its scientificapplications, translated by Ali VahidianKamyad and Hamed Reza Tareghian, publications of Ferdowsi Universityof Mashhad, Second edition. 
Egai, W. T. (2003). Selecting the websit for on line advertising using AHP, Information \& Management.

Wells, B. M. (2004). Commercial advertising, translated by SeenaGhorbanlou, Moballeghan publications, First edition.

William, W., et al. (2005). Principles and Practice of Advertising . Eastern Economy.

Zaim, S., Sevkli, M., \& Tarim, M. (2003). Fuzzy AnayticJierarchy based approach for supplier selection, Fatih University, Department of Management.

\section{Copyrights}

Copyright for this article is retained by the author(s), with first publication rights granted to the journal.

This is an open-access article distributed under the terms and conditions of the Creative Commons Attribution license (http://creativecommons.org/licenses/by/3.0/). 